\title{
Comparison of the haemodynamic effects of epoprostenol (prostacyclin) and tolazoline
}

\author{
A BUSH, C M BUSST, W B KNIGHT, * E A SHINEBOURNE* \\ From the Departments of Respiratory Physiology and *Paediatric Cardiology, Brompton Hospital, London
}

SUMMARY The haemodynamic effects of infusion of epoprostenol (prostacyclin) and bolus injection of tolazoline were compared in a crossover study in 11 children with pulmonary hypertension caused by pulmonary vascular disease. The children were studied during cardiac catheterisation, while they were anaesthetised, paralysed, and ventilated with $100 \%$ oxygen. The order of drug administration was not randomised because tolazoline has a half life of hours whereas epoprostenol has a half life of a few minutes. Both drugs caused pulmonary and systemic vasodilatation, and there were no significant differences between the two. The $95 \%$ confidence intervals suggest that tolazoline did not have a clinically important haemodynamic advantage over epoprostenol. Previous reports suggest that serious side effects are common when tolazoline is used in repeated doses; epoprostenol has only a few minor side effects that are rapidly reversible when the infusion is stopped.

Epoprostenol is more expensive than tolazoline but this study suggests that epoprostenol is a more suitable pulmonary vasodilator if more than a single dose is required.

Tolazoline is an $\alpha$ adrenergic antagonist and $\mathbf{H}_{2}$ agonist agent that has been widely used in infants and children for the preoperative assessment of congenital heart disease, ${ }^{1}$ the management of postoperative pulmonary hypertensive crises, ${ }^{2}$ and pulmonary hypertension caused by pulmonary parenchymal disorders. ${ }^{3}$ It is not an ideal agent, however, because of the prevalence and severity of side effects, and its prolonged duration of action. Depending on the dose used, $30 \%-80 \%$ of infants treated with tolazoline infusion have side effects, which may contribute to mortality. ${ }^{46}$ These include hypotension, ${ }^{7}$ thrombocytopenia, pulmonary and gastrointestinal haemorrhage, seizures, oliguria and renal failure severe enough to necessitate peritoneal dialysis, ${ }^{89}$ haematuria, hyponatraemia, abdominal distension, and duodenal perforation. ${ }^{4510}$ The half life of the drug ranges from 90 minutes to more than $\mathbf{4 0}$ hours and is inversely proportional to the urine flow rate. ${ }^{11}$

We have previously shown that epoprostenol (prostacyclin) is a pulmonary vasodilator in children with congenital heart disease ${ }^{12}$ and bronchopulmonary dysplasia. ${ }^{13}$ It has a half life of minutes and few

Requests for reprints to Dr E A Shinebourne, Department of Paediatric Cardiology, Brompton Hospital, Fulham Road, London SW3 6HP.

Accepted for publication 8 December 1987 side effects. These are rapidly reversible when the infusion is stopped. ${ }^{14}$ These features may make epoprostenol a safer agent than tolazoline. We therefore carried out a study to compare the haemodynamic effects of these two drugs.

\section{Patients and methods}

\section{PATIENTS}

Table 1 shows the details of the 11 children studied. All had raised pulmonary vascular resistance $(>3$ $\mathrm{mm} \mathrm{Hg} \cdot \mathrm{l}^{-1}$. min. $\mathrm{m}^{2}$ ) during ventilation with $100 \%$ oxygen. In nine patients this increase was primarily the result of congenital heart disease, and in two the main diagnosis was bronchopulmonary dysplasia. The response of the pulmonary circulation to vasodilators was studied as part of the preoperative or prognostic assessment of pulmonary vascular disease or to optimise vasodilator treatment used in the management of pulmonary hypertensive crises. No child had a ductus arteriosus at the time of study. Children 2 and 8 had undergone palliative Mustard operations before the study. Informed consent was obtained from the parents of all the patients before the procedure, and the protocol was approved by the Brompton Hospital ethics committee.

METHODS

Full details of the measurement techniques have 
Table 1 Details of patients studied, given in descending order of baseline pulmonary vascular resistance (PVR)

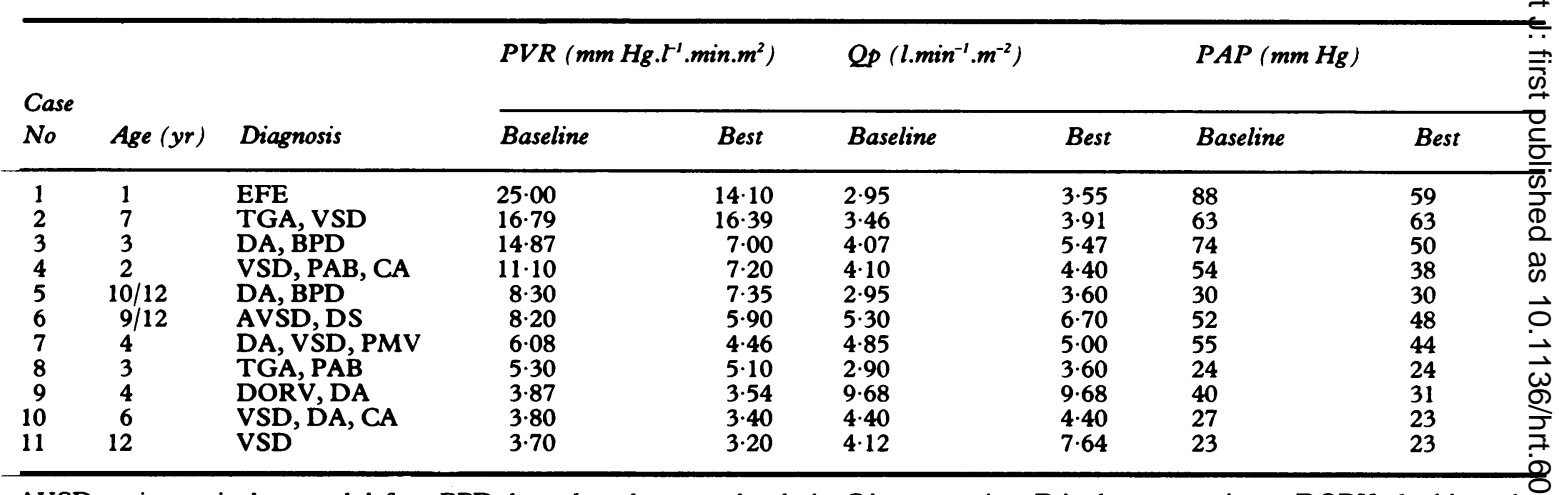

AVSD, atrioventricular septal defect; BPD, bronchopulmonary dysplasia; CA, coarctation; DA, ductus arteriosus; DORV, double outlqं: right ventricle; DS, Down's syndrome; EFE, endocardial fibroelastosis; PAB, pulmonary artery banded; PAP, pulmonary artery pressure, PMV, parachute mitral valve; Qp, pulmonary blood flow; TGA, transposition of the great arteries; VSD, ventricular septal defect.

been reported elsewhere. ${ }^{15} 16$ In summary, the children were anaesthetised with intravenous etomidate throughout the study. They were paralysed and ventilated via a close-fitting endotracheal tube. The stability and adequacy of ventilation throughout the study were monitored by mass spectrometry of end tidal gases. The children were initially ventilated with air. Fluid filled catheters were introduced percutaneously into the femoral artery and vein and positioned in the aorta and pulmonary artery respectively. Any necessary diagnostic procedures, including measurement of left and right atrial pressures but excluding angiography, were performed before the measurements were made.

When a respiratory steady state had been reached (that is an end tidal $\mathrm{PCO}_{2}$ stable to within $0.25 \mathrm{kPa}$ over several minutes) ${ }^{16}$ we measured aortic and pulmonary artery pressure and pulmonary and (where possible) systemic blood flow. We measured flow by the direct Fick principle. Oxygen consump- tion was measured by remote respiratory mass spec은 trometry, ${ }^{1516}$ and blood oxygen content was cal $\vec{\nabla}$ culated by the subroutine of Kelman. ${ }^{17}$ The res piratory exchange ratio was measured on air and was used in the equation to calculate oxygen consumption on $100 \%$ oxygen. ${ }^{16}$

After the measurements on air, the children were ventilated with $100 \%$ oxygen. Ventilation and adequacy of nitrogen washout on air and oxygen were compared by monitoring the expired gases. After 18 minutes on $100 \%$ oxygen, when nitrogen washouf was always complete, all measurements werE్ repeated. The patients breathed $100 \%$ oxygen for the rest of the study.

After the measurements on $100 \%$ oxygen alone were completed (baseline 1), the vasodilators were administered. Figure 1 summarises the protocolis Because of the differences in half life, we always had to administer epoprostenol before tolazoline. We gave epoprostenol by continuous intravenous

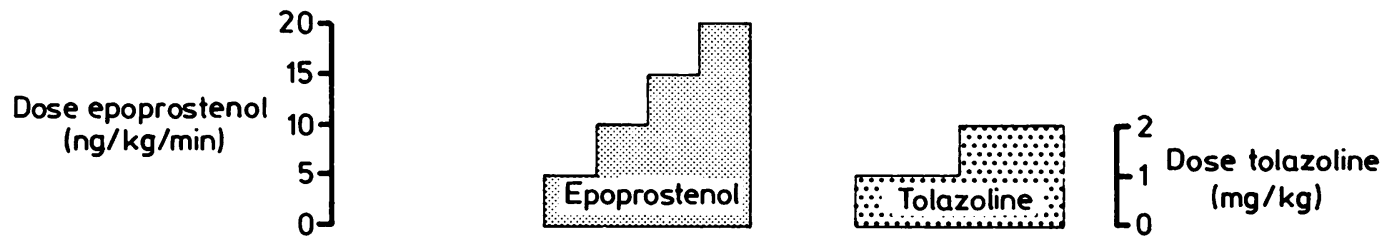

Inspired gas

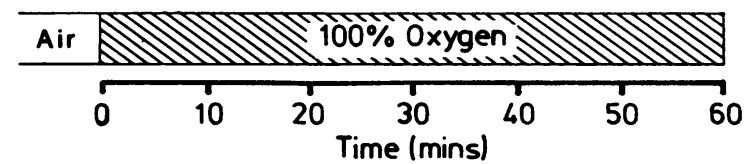

Measurements

Then at 5 minute intervals

Fig 1 The study protocol. Measurements were made while the patient breathed air, after breathing $100 \%$ oxygen for ten minutes, and every five minutes thereafter. Epoprostenol was given by continuous intravenous infusion and tolazoline by bolus injection into the pulmonary artery. 
infusion into a peripheral vein and started with a dose of $5 \mathrm{ng} / \mathrm{kg} / \mathrm{min}$. This was increased by increments of $5 \mathrm{ng} / \mathrm{kg} / \mathrm{min}$ until a dose of $20 \mathrm{ng} / \mathrm{kg} / \mathrm{min}$ was reached. Measurements were made after five minutes at each dose level. We would have stopped the infusion if mean aortic pressure had fallen by more than $20 \mathrm{~mm} \mathrm{Hg}$, but this was never necessary. When the final epoprostenol measurements were complete the infusion was stopped. The measurements were then made five and ten minutes after the drug had been stopped. The results at 10 minutes were regarded as baseline 2 . Then we gave tolazoline $1 \mathrm{mg} / \mathrm{kg}$ as a bolus injection via the pulmonary artery catheter. The measurements were repeated five and ten minutes after the bolus $(n=11)$. Provided mean aortic pressure had not fallen by more than $20 \mathrm{~mm} \mathrm{Hg}$, a further $1 \mathrm{mg} / \mathrm{kg}$ of tolazoline was then given and the final measurements were made five and ten minutes after this second bolus $(n=8)$. In two patients the second dose was not given because of hypotension, and in the third it was not given because the endotracheal tube was becoming blocked with secretions and the necessary endotracheal toilet disrupted the respiratory steady state.

\section{STATISTICAL ANALYSIS}

Table 1 shows that there were big differences in the initial pulmonary haemodynamic function in the patients studied. This variability was removed by subtracting the initial measurement made on $100 \%$ oxygen alone from all subsequent measurements, so that analysis was restricted to the change in the variables. These data were inspected and found to be normally distributed. The mean and the $95 \%$ confidence intervals were calculated for each set of measurements.

It is possible to compare the tolazoline results either with the first baseline on $100 \%$ oxygen, before any drugs were given (B1 in the figures), or with the second baseline, 10 minutes after epoprostenol and just before tolazoline was given (B2b in the figures). We also had to decide whether to analyse the 11 sets of data that included measurements of the effects of only the first dose of tolazoline or the eight complete sets of data that included both doses of tolazoline. We decided to perform all four combinations of analyses to see whether the choice of numbers or baseline materially affected the conclusions. Thus the comparisons for pulmonary vascular resistance, pulmonary blood flow, pulmonary artery pressure, heart rate, and aortic pressure were (first baseline minus maximal epoprostenol effect) versus (first baseline minus maximal tolazoline effect) for $n=11$ and $n=$ 8; and (first baseline minus maximal epoprostenol effect) versus (second baseline minus maximal tolazoline effect) for $n=11$ and $n=8$. Differences between drug effects were also normally distributed and were also expressed as mean and $95 \%$ confidence intervals of the difference.

The comparisons for systemic blood flow, systemic vascular resistance, and the ratio of pulmonary and systemic vascular resistances are based on only six sets of data because systemic blood flow can only be measured accurately by the Fick principle if a truly mixed venous blood sample can be obtained..$^{18}$ This is not possible if there is left to right shunting. Only four of these six patients were given the second dose of tolazoline. Data for the second dose were not analysed because the numbers are so small. For these variables, the comparisons were (first baseline minus maximal epoprostenol effect) versus (first baseline minus maximal tolazoline effect) $(n=6)$; and (first baseline minus maximal epoprostenol effect) versus (second baseline minus maximal tolazoline effect) $(n=6)$. The data for individuals were inspected to see how many patients had the greatest change in pulmonary vascular resistance, aortic pressure, and heart rate on epoprostenol and how many on tolazoline. The significance of these differences was assessed by a test of proportions.

\section{Results}

Figures 2 to 9 show the mean and $95 \%$ confidence intervals for the changes in pulmonary vascular

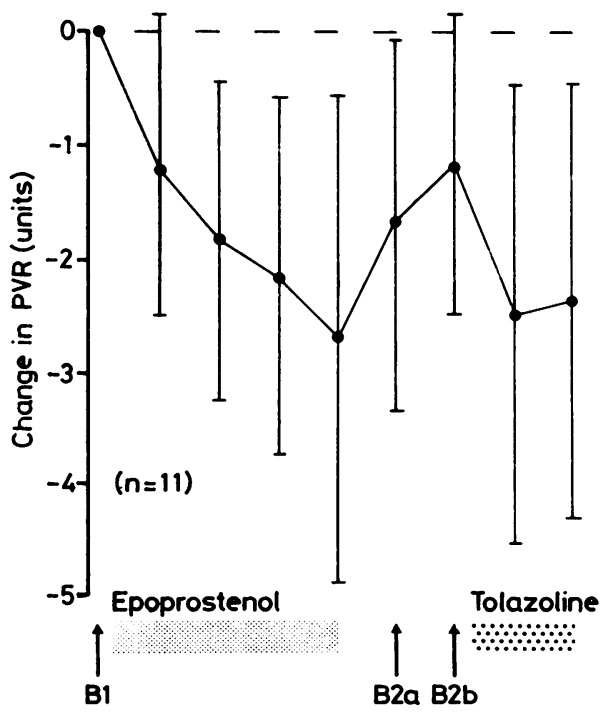

Fig 2 Change (mean, 95\% CI) in pulmonary vascular resistance $(P V R)$ with epoprostenol and tolazoline. In this and figs 3 to 9, B1 is the baseline measurement on $100 \%$ oxygen before any drugs were given and $B 2 a$ and $B 2 b$ the baselines respectively five and ten minutes after stopping the infusion of epoprostenol. 


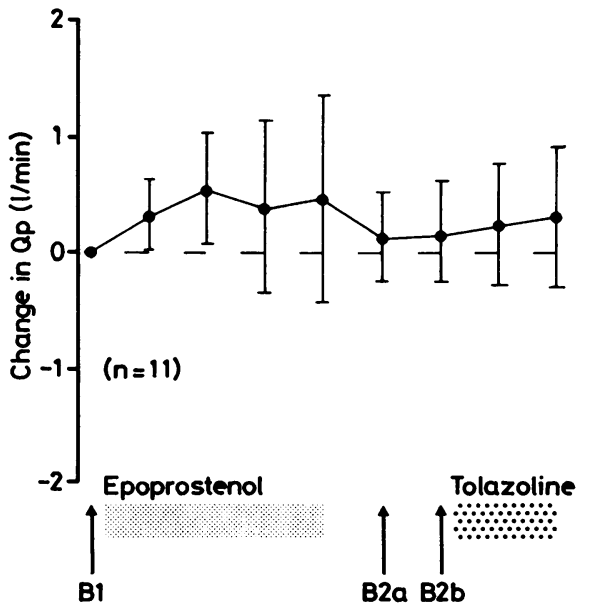

Fig 3 Change (mean, 95\% CI) in pulmonary blood flow $(Q p)$ with epoprostenol and tolazoline infusions.

resistance, pulmonary blood flow, pulmonary artery pressure, heart rate, aortic pressure, systemic vascular resistance, systemic blood flow, and the ratio of pulmonary to systemic vascular resistances. The results for the second dose of tolazoline are not plotted because they are incomplete. In summary, there were significant falls in pulmonary vascular resistance on both drugs (fig 2), a significant rise in heart rate with tolazoline and a trend to rise with epoprostenol (fig 5), and significant falls in systemic vascular resistance with both drugs (fig 8 ). Neither drug caused a significant change in the ratio of pulmonary to systemic vascular resistance (fig 9).

Tables 2 and 3 show the mean and the confidence intervals of the differences between the drugs, analysed as described above. If epoprostenol caused a

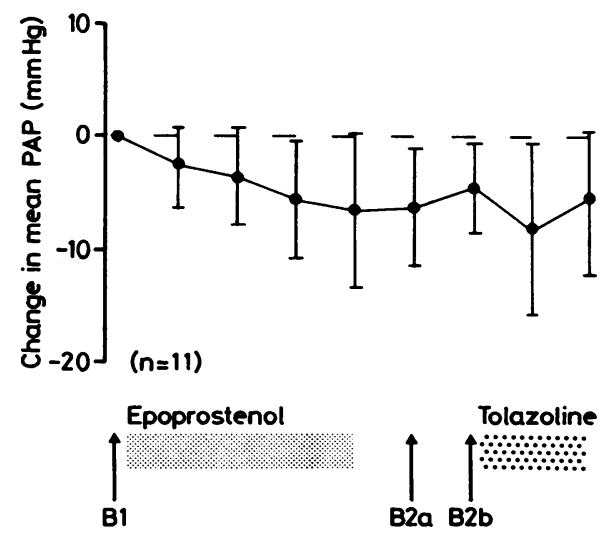

Fig 4 Change (mean, 95\% CI) in mean pulmonary artery pressure $(P A P)$ with epoprostenol and tolazoline infusions.

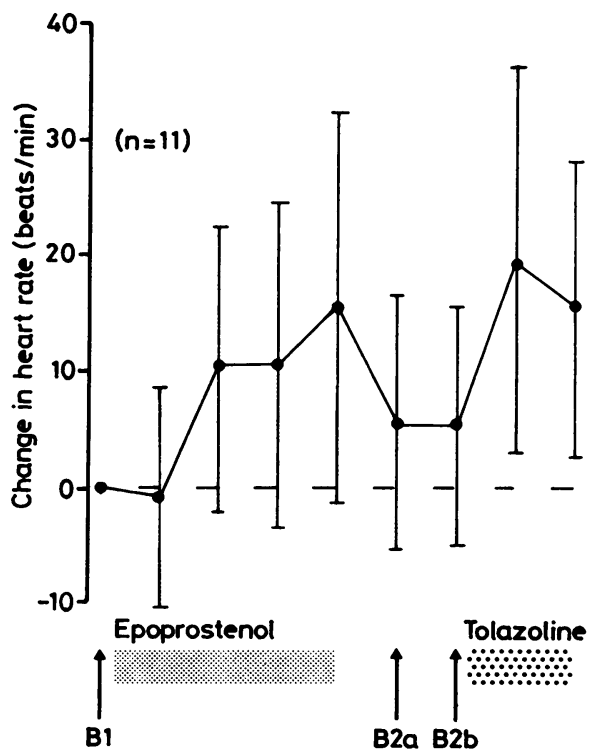

Fig 5 Change (mean, 95\% CI) in heart rate with epoprostenol and tolazoline infusions.

greater change than tolazoline the change was given a positive value; if tolazoline caused a greater changeo than epoprostenol the change was given a negatives value. The method of analysis did not materially altero the conclusions, which are summarised below. Theo results in the tables were combined by selecting the biggest positive and negative value for each drug for each physiological measurement-that is, the most extreme values for each drug for each row in the tables irrespective of the method of analysis. This

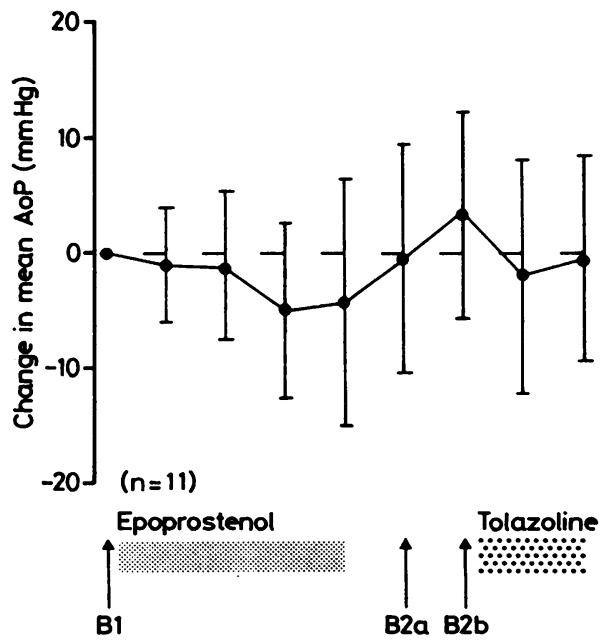

Fig 6 Change (mean, 95\% CI) in mean aortic pressure (AoP) with epoprostenol and tolazoline infusions. 

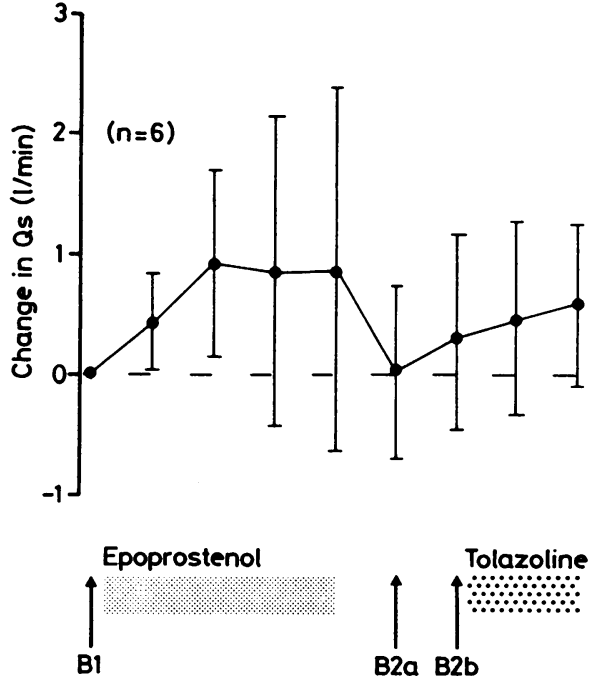

Fig 7 Change (mean, 95\% CI) in mean systemic blood flow (Qs) with epoprostenol and tolazoline infusions.
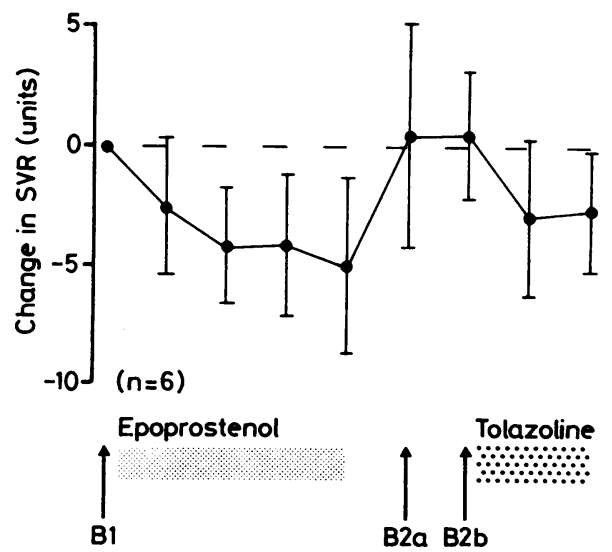

Fig 8 Change (mean, 95\% CI) in systemic vascular resistance (SVR) with epoprostenol and tolazoline infusions.

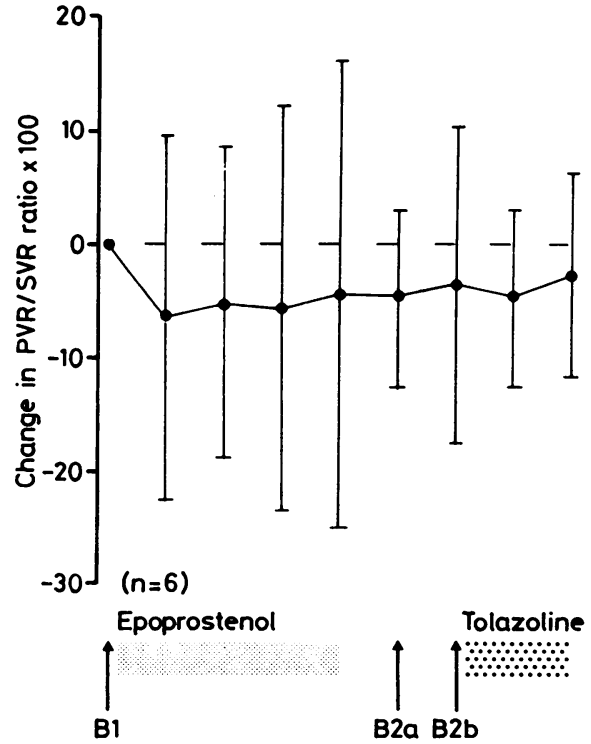

Fig 9 Change (mean, 95\% CI) in the ratio of pulmonary to systemic vascular resistance $\times 100(P V R / S V R$ ratio $)$ with epoprostenol and tolazoline infusions.

range of values is $95 \%$ certain to include the true value. The confidence intervals would have been narrower if only one column had been selected from the tables and the others had been excluded. The biggest positive value was the "best case" for epoprostenol and the biggest negative value was the "best case" for tolazoline. The direction of the effects (increase or decrease over baseline) is shown in figs 2 to 9.

On this basis, the confidence intervals for the differences between the drug effects on pulmonary vascular resistance are 4.01 to -0.74 units, for pulmonary blood flow 2.08 to $-0.22 \mathrm{1} / \mathrm{min}$, and for mean pulmonary artery pressure 12.5 to -4.8 $\mathrm{mm} \mathrm{Hg}$. The heart rate intervals are 11.3 to -18.7 beats/min. For the systemic circulation, the con-

Table 2 Mean and $95 \%$ confidence intervals for the changes in pulmonary vascular resistance (units, PVR), pulmonary blood flow (l/min, $Q p)$ pulmonary artery pressure ( $\mathrm{mm} \mathrm{Hg}, P A P)$, heart rate (beats/min, $H R$ ), and aortic pressure (mm $\mathrm{Hg}, A o P)$. ( $A$ minus sign means that the magnitude of the change was greatest with tolazoline)

\begin{tabular}{|c|c|c|c|c|}
\hline & \multicolumn{2}{|l|}{ Baseline 1} & \multicolumn{2}{|l|}{ Baseline 2} \\
\hline & $n=11$ & $n=8$ & $n=11$ & $n=8$ \\
\hline $\begin{array}{l}\text { PVR } \\
\text { Qp } \\
\text { PAP } \\
\text { HR } \\
\text { AoP }\end{array}$ & $\begin{array}{l}0.22(0.88 \text { to }-0.44) \\
0.53(1.15 \text { to }-0.09) \\
-0.2(4.4 \text { to }-4.8) \\
-3.5(0.9 \text { to }-7.9) \\
6.5(15.0 \text { to }-2.0)\end{array}$ & $\begin{array}{l}0.20(1.14 \text { to }-0.74) \\
0.66(1.54 \text { to }-0.22) \\
0.3(4.7 \text { to }-4 \cdot 1) \\
-9.6(-0.5 \text { to }-18 \cdot 7) \\
7.0(15.3 \text { to }-1.3)\end{array}$ & $\begin{array}{l}1.39(3.16 \text { to }-0.38) \\
0.71(1.53 \text { to }-0.11) \\
4.4(10.5 \text { to }-1.7) \\
1.8(11.3 \text { to }-7.7) \\
3.2(12.5 \text { to }-6.1)\end{array}$ & $\begin{array}{c}1.75(4.01 \text { to }-0.51) \\
0.98(2.08 \text { to }-0.12) \\
5.3(12.5 \text { to }-1.9) \\
-1.8(7.8 \text { to }-11.4) \\
6.6(16.2 \text { to }-3.0)\end{array}$ \\
\hline
\end{tabular}

Baseline 1, tolazoline effects compared with baseline before any drugs given (B1 in figures); baseline 2, tolazoline effects compared with second baseline 10 minutes after epoprostenol was stopped and before tolazoline was given (B2b in figures). $\mathrm{n}=11,11$ sets of data analysed; these included only the first dose of tolazoline; $n=8$, analysis of the eight sets of data that included both doses of tolazoline. 
Table 3 Mean and $95 \%$ confidence intervals for the changes in systemic blood flow (Qs), systemic vascular resistance ( $S V R$ ), and the ratio of pulmonary to systemic vascular resistance ( $P V R / S V R$ ratio)

\begin{tabular}{lll}
\hline & Baseline 1 & Baseline 2 \\
\hline Qs (1/min) & $0.51(1.37$ to -0.35$)$ & $0.84(2.39$ to -0.71$)$ \\
SVR (units) & $2.53(6.42$ to -1.36$)$ & $2.07(6.86$ to -2.72$)$ \\
PVR/SVR ratio & $0.04(0.19$ to -0.11$)$ & $0.07(0.12$ to 0.02$)$ \\
\hline
\end{tabular}

All comparisons were based on six patients, and the data for the second dose of tolazoline ( $n=4$ only) were discarded. Baseline 1 and baseline 2 , see table 2 .

fidence intervals are $16 \cdot 2$ to $-6 \cdot 1 \mathrm{~mm} \mathrm{Hg}$ for aortic pressure, 2.39 to $-0.71 \mathrm{1} / \mathrm{min}$ for systemic blood flow, and 6.86 to -2.72 units for systemic vascular resistance. The confidence intervals for the change in ratio of pulmonary to systemic vascular resistance are $0 \cdot 19$ to $-0 \cdot 11$.

The individual data were assessed separately. Epoprostenol caused the greater fall in pulmonary vascular resistance in $7 / 11(8 / 11$ if tolazoline is compared with the second baseline), a greater fall in aortic pressure in $8 / 11(7 / 11$, second baseline), and a greater rise in heart rate in $2 / 11$ (9/11 second baseline).

\section{Discussion}

Before drawing any conclusions from the findings described above, the study design must be considered in detail. This discussion centres on the inevitable difficulties of this sort of comparison and the ways of interpreting the results.

The classic method of comparing these two agents would be to use two large matched groups of patients, and allocate at random one group to receive tolazoline and one to receive epoprostenol. This was rejected, because matching for age, cardiac diagnosis, baseline pulmonary vascular resistance, and reactivity for two groups of sufficient size would be impossible. We therefore decided to use a crossover design and give both drugs to all patients. Ideally, the order would have been randomised, but because tolazoline has a half life of many hours ${ }^{11}$ and epoprostenol one of a few minutes, ${ }^{14}$ epoprostenol always had to be administered first. The resulting problems of order effects and possible interactions between the drugs are discussed below; we adopted this design as the best compromise between what was ethically possible and experimentally desirable. Also the inspired oxygen tension needed to be the same for both drugs. Because we wanted to detect the lowest pulmonary vascular resistance for each individual for clinical purposes, we decided to use $100 \%$ oxygen, which has been shown to be additive to the effects of both epoprostenol $^{1213}$ and tolazoline. ${ }^{19}$
Bush, Busst, Knight, Shinebourn $\bar{\Phi}$

The initial part of the study confirms previou results, ${ }^{12}{ }^{13}$ and the interpretation is straightforward:Epoprostenol, when added to $100 \%$ oxygen, caused further fall in pulmonary vascular resistance, with systemic hypotension and tachycardia. When the infusion was stopped, these variables reverte towards baseline. Ten minutes after stopping the infusion, mean pulmonary artery pressure was still a mean $4.5 \mathrm{~mm} \mathrm{Hg}$ ( $95 \%$ confidence interval 8.4 to 0.6$)$ below baseline. The other variables were not sig $\overrightarrow{0}$ nificantly different from baseline. Pulmonary vascular resistance was furthest from the baseline largely owing to the results from three individuals whom reversal was abnormally slow. When thes three were omitted, the means \pm and $95 \%$ cone fidence intervals five and ten minutes after the end of the infusion were $-0.33(-0.87$ to 0.21$)$ and -0.13 $(-0.9$ to +0.64$)$ units. We do not know why threo patients should have apparently behaved differently $\vec{j}_{\dot{2}}$ but in general, these results confirm that the half life of epoprostenol is short. ${ }^{14}$

The interpretation of subsequent measurements is less straightforward. It is possible that all the effects seen can be attributed solely to tolazoline. But some residual minor effects of epoprostenol may have interacted favourably or unfavourably with those 06 tolazoline. It is also possible that the prolongee anaesthesia, or exposure to hyperoxia, caused some of the changes we saw. The return of most of the measured variables nearly to the original baseline makes it unlikely that these are major factors. Never $\overrightarrow{\overrightarrow{0}}$ theless, because the drugs were always given in the same order, such effects cannot be excluded. Fur thermore, although for the group the baseline. measurements before and after the administration of epoprostenol were similar, there was individuat variation, and perhaps it would be better to refer the tolazoline measurements to the original baseline or to. the baseline attained just before it was given Therefore, we analysed the tolazoline results by reference to each baseline in turn for the eighs complete sets of data (both doses of tolazolins administered) and the eleven sets (the first dose of tolazoline). The mean differences and their con fidence intervals are similar whichever analysis is chosen.

The results confirm that epoprostenol and tolazoline when added to $100 \%$ oxygen result i systemic and pulmonary vasodilatation and tachycardia..$^{1320}$ We were unable to detect sige nificant differences between the haemodynamis effects of these two drugs. The confidence interval\$ can be used to assess the likelihood that a clinicallo significant difference was present but not detecte@ Tolazoline may have reduced the pulmonary vas cular resistance by less than one unit more than 
epoprostenol. Even if such a difference were genuine, it would be unlikely to be clinically important. Epoprostenol may have reduced pulmonary vascular resistance by up to 4 units more than tolazoline-a difference that would be clinically important. It is also possibile, however, that epoprostenol causes more clinically significant systemic hypotension than tolazoline. One method of trying to assess the selectivity of an agent for the pulmonary circulation is to look at the ratios of pulmonary resistance to systemic vascular resistance. The mean and confidence intervals suggest that there is no real difference between the two agents, and that it is unlikely that such a difference was present but not detected.

The data for individual patients show that slightly more subjects had a greater reduction in pulmonary vascular resistance and aortic pressure with epoprostenol than with tolazoline; but these differences are also unlikely to be significant. It seems more likely that reactive pulmonary vessels will be dilated by any vasodilator agent. There is no reason to suppose that any particular class of drug is likely to be more effective for a substantial number of patients.

Some workers have reported increased haemodynamic benefit with doses of tolazoline of up to $10 \mathrm{mg} /$ kg. ${ }^{4121}$ If we had given higher doses to these children the conclusions might have been different. Side effects may be dose related, however, and at these high doses cause considerable toxicity. Two $(18 \%)$ of our 11 patients had hypotension at a dose of $1 \mathrm{mg} / \mathrm{kg}$ of tolazoline and three $(27 \%)$ out of eight had hypotension at a dose of $2 \mathrm{mg} / \mathrm{kg}$. Administration of doses as high as $10 \mathrm{mg} / \mathrm{kg}$ cannot be regarded as standard practice. ${ }^{22}$

We did not detect a major difference between the two drugs, and the confidence intervals suggest that tolazoline at doses of $1-2 \mathrm{mg} / \mathrm{kg}$ is unlikely to offer a clinically important, haemodynamic advantage over epoprostenol. It is possible but not confirmed that in the doses used epoprostenol is a more powerful pulmonary and systemic vasodilator than tolazoline. The choice between the two drugs can therefore be made on other grounds.

In this short term study, neither drug had serious side effects. Because a dose of $1 \mathrm{mg} / \mathrm{kg}$ of tolazoline caused hypotension in two patients we were unable to give a second bolus but no patient required treatment for hypotension. Repeated doses of tolazoline are often associated with severe side effects that may be a contributory cause of death. In addition, its long half life ${ }^{11}$ means that any side effects can persist for many hours. By contrast, the side effects of epoprostenol are rapidly reversible when the infusion is stopped. ${ }^{14}$ The major side effect is hypotension, but others, such as headache and facial flushing, ${ }^{142}$ are unlikely to be important in patients who are being ventilated. The main disadvantage of epoprostenol is its cost; a single vial costs more than $£ 100$ and 24 hours treatment more than $£_{200}$, whereas treatment for the same period with tolazoline costs $£ 10$. It is safer to give epoprostenol; but for single doses for the preoperative assessment of congenital heart disease the risk of side effects is low enough to allow tolazoline to be used because it is cheaper. If more than a single dose is required, for example in the postoperative management of pulmonary hypertensive crisis, epoprostenol should probably be used first, and tolazoline used only if satisfactory results cannot be obtained with epoprostenol. Tolazoline reduced pulmonary vascular resistance more than epoprostenol in only three patients. Neither agent is likely to be suitable for outpatient treatment of children, for whom oral pulmonary vasodilators are more suitable. Long term domiciliary intravenous infusion of epoprostenol has, however, been used to treat adults with primary pulmonary hypertension. ${ }^{24}$

We found that the haemodynamic effects of epoprostenol and tolazoline were similar in children with a high pulmonary vascular resistance complicating congenital heart disease. Earlier reports suggest that tolazoline has more severe side effects. Epoprostenol is more expensive; none the less we suggest that epoprostenol should replace tolazoline as a pulmonary vasodilator in these children, except possibly where only a single dose is needed.

We thank Dr Colin Chalmers, University of London, for advice on the statistical analysis.

A B is supported by the British Heart Foundation.

\section{References}

1 Dresdale DT, Schultz M, Michtom RJ. Primary pulmonary hypertension. Am J Med 1951;11:686-705.

2 Jones ODH, Shore DF, Rigby ML, et al. The use of tolazoline hydrochloride as a pulmonary vasodilator in potentially fatal episodes of pulmonary vasoconstriction after cardiac surgery in children. Circulation 1981;64 (suppl II):134-9.

3 Goetzman BW, Sunshine P, Johnson JD, et al. Neonatal hypoxia and pulmonary vasospasm: response to tolazoline. J Pediatr 1979;89:617-21.

4 Stevenson DK, Kasting DS, Darnall RA, et al. Refractory hypoxemia associated with neonatal pulmonary disease: the use and limitations of tolazoline. J Pediatr 1979;95:595-9.

5 Stevens DC, Schreiner RL, Bull MJ, et al. An analysis of tolazoline therapy in the critically-ill neonate. $J$ Pediatr Surg 1980;15:964-70.

6 Heath RE. Vasospasm in the neonate: response to 
tolazoline infusion. Pediatrics 1986;77:405-8.

7 McIntosh N, Walters RO. Effects of tolazoline in severe hyaline membrane disease. Arch Dis Child 1979; 54:105-10.

8 Bhat R, Gupta M, John E, Vidyasagar D. Acute renal failure in newborn due to priscoline [Abstract]. Pediatr Res 1978;12:519.

9 Trompeter RS, Chantler C, Haycock GB. Tolazoline and acute renal failure in the newborn [Letter]. Lancet $1981 ; \mathbf{i}: 1219$.

10 Wilson RG, George RJ, McCormick WJ, Raine PAM. Duodenal perforation associated with tolazoline. Arch Dis Child 1985;60:878-9.

11 Ward RM, Daniel CH, Kendig JW, Wood MA. Oliguria and tolazoline pharmacokinetics in the newborn. Pediatrics 1986;77:307-15.

12 Bush A, Busst CM, Booth K, Knight WB, Shinebourne EA. Does prostacyclin enhance the selective pulmonary vasodilator effect of $100 \%$ oxygen? Circulation 1986;74:135-44.

13 Bush A, Busst CM, Knight WB, Shinebourne EA. Cardiopulmonary interactions in infants with bronchopulmonary dysplasia (BPD). [Abstract]. Atemwegs-und Lungenkrankheiten 1987;3:140.

14 O'Grady J, Warrington S, Moh MJ, et al. Effects of intravenous infusions of prostacyclin (PG12) in man. Prostaglandins 1980;19:319-32.

15 Davies NJH, Denison DM. The measurement of metabolic gas exchange by mass spectrometry alone. Respir Physiol 1979;36:261-7.
16 Davies NJH, Shinebourne EA, Scallan MJ, Sopwith TA, Denison DM. Pulmonary vascular resistance if children with congenital heart disease. Thora 1984;39:895-900.

17 Kelman GR. Digital computer subroutine for the conversion of oxygen tension into oxygen saturation? J Appl Physiol 1966;21:1375-6.

18 Harris P, Heath D. The human pulmonary circulation 3rd ed. London: Churchill Livingstone, 1986:95

19 Kelminson LL, Cotton EK, Vogel JHK. The rever" sibility of pulmonary hypertension in patients with cystic fibrosis. Observations on the effects of tolazoline hydrochloride. Pediatrics 1969;39:24-35.

20 Bush A, Busst CM, Knight WB, Shinebourne EA Cardiovascular effects of tolazoline and ranitidine Arch Dis Child 1987;62:241-6.

21 Adams JM, Hyde WH, Procianoy RS, Rudolph A Hypochloremic metabolic alkalosis following tolazoline-induced gastric hypersecretion. Pediatrics 1980;65:298-300.

22 Reynolds JGF, ed. Martindale: The extra phar= macopoeia. 28th ed. London: The Pharmaceuticat Press, 1982:1633.

23 Eklund B, Joreteg T, Kaijser L. Dissimilar effects of prostacyclin on cardiac output and forearm blood flow in healthy men. Clin Physiol 1981;1:123-30.

24 Jones DK, Higenbottam TW, Wallwork J. Treatmento of primary pulmonary hypertension with intravenous epoprostenol (prostacyclin). Br Heart J 1987;57\% 270-8. 